\title{
Hydrothermal synthesis of spindle-like architectures of terbium hydroxide
}

\author{
Hongjuan ZHENG, Kazumichi YANAGISAWA, ${ }^{\dagger}$ Ayumu ONDA and Kongjun ZHU* \\ Research Laboratory of Hydrothermal Chemistry, Faculty of Science, Kochi University, 2-5-1 Akbono-cho, Kochi 780-8520, Japan \\ *State Key Laboratory of Mechanics and Control of Mechanical Structures, Nanjing University of Aeronautics and Astronautics, \\ Nanjing 210016, P. R. China
}

\begin{abstract}
The spindle-like architectures consisting of $\mathrm{Tb}(\mathrm{OH})_{3}$ nanowires were successfully prepared from $\mathrm{Tb}_{2} \mathrm{O}_{3}$ powder by hydrothermal treatments in acetic acid solutions without adding other surfactants. The products were characterized by XRD, FE-SEM and FTIR. The influence of the concentration of acetic acid, reaction temperature and reaction time on the crystalline phases and morphologies of the products was investigated. The concentration of acetic acid plays a key role in determining the morphology of the $\mathrm{Tb}(\mathrm{OH})_{3}$ products. The effect of acetic acid on the morphologies of the products was systematically discussed.

(C)2015 The Ceramic Society of Japan. All rights reserved.
\end{abstract}

Key-words : Terbium hydroxide, Nanowires, Spindle, Rare earth, Hydrothermal

[Received May 15, 2015; Accepted June 8, 2015]

\section{Introduction}

Rare-earth elements form a group in the periodic table, consisting of 17 metallic elements with chemical similarities, including the scandium and yttrium plus 15 lanthanides. The rare-earth compounds have been extensively used in various fields owing to their excellent optic, magnetic, electric, and catalytic properties resulting from their unique $4 \mathrm{f}$ electronic structures. ${ }^{1)}$ However, the properties of the functional materials strongly depend on the compositions, crystalline phases, morphology and dimensionality of the as-prepared products. ${ }^{2)}$ Recently, many kinds of rare-earth compounds with different dimensions, including oxides, hydroxides, phosphates, borates and fluorides have been prepared to generate unexpected properties. ${ }^{3)-6)}$ Among them, the nanowire is an important material as a result of quantum confinement effects, which exhibit significant physical and chemical properties differing from the bulk materials. Nowadays, nano-scale particles of terbium oxides are one of the important functional rare earth materials among the family of the rare earth compounds. Terbium oxides have been widely used in high performance luminescent devices, magnets, catalysts, and other functional materials. ${ }^{7)-9)}$ According to the previous report, ${ }^{10)}$ rare earth oxides can be directly formed through dehydration of the corresponding hydroxides, and the oxides can retain the morphology of the hydroxides. Therefore, preparation of rare-earth hydroxides with various morphologies is of great importance.

Hydrothermal method is an excellent way to synthesize functional materials with excellent properties, due to its low cost, environmental friendship, and easy control in terms of purity and morphology of the final products. ${ }^{11-15)}$ Generally, the hydrothermal process of controlled construction of architectures needs the aid of surfactants or template reagents. Yang and $\mathrm{Li}$ et al. ${ }^{16)}$ synthesized $\mathrm{Ln}^{3+}$-doped lutetium oxide precursor with flowerlike microarchitectures by a hydrothermal process with the assistance of ethylene glycol; Wang and Bai et al. ${ }^{17)}$ used oleylamine as a

$\dagger$ Corresponding author: K. Yanagisawa; E-mail: yanagi@kochi-u. ac.jp surfactant to synthesize layered lanthanide ( $\mathrm{Pr}, \mathrm{Nd}, \mathrm{Sm}, \mathrm{Eu}$ and Gd) hydroxide nanowires; Tang and Shen et al. ${ }^{7)}$ used sodium dodecyl benzenesulfonate (SDBS) as template reagent to synthesize terbium hydroxide nanotubes. There are many surfactants frequently used, such as polyvinylpyrrolidone (PVP), ${ }^{2)}$ cetaltrimethyl ammonium bromide (CTAB), ${ }^{9)}$ and ethylenediamine. ${ }^{18)}$

It's worth noting that the rare earth hydroxides are usually obtained by the above-mentioned method through two steps, which consist of the dissolution of oxides and precipitation of precursor colloids by adding a basic solution as precipitators before hydrothermal treatment. Thus, the surfactants or template reagents directly reach out to hydroxide precursors. In the present study, we exploited a one-step hydrothermal route using terbium oxide as a raw material by adjusting the concentration of acetate acid without adding any surfactants to prepare the spindle-like architectures of terbium hydroxide. The influence of the concentration of acetic acid, reaction temperature and reaction time on the crystalline phase and morphologies of products was systematically investigated. In addition, a possible formation mechanism for the morphological evolution of these microstructures was discussed.

\section{Experimental}

\subsection{Preparation of $\mathrm{Tb}(\mathrm{OH})_{3}$}

All chemicals with analytical grade were purchased from Wako Pure Chemical Industries, Ltd., Japan, and used without further treatment. A detailed description of the preparation process is as follows:

$15 \mathrm{~mL}$ of acetic acid $\left(\mathrm{CH}_{3} \mathrm{COOH}\right)$ solution with different concentrations $(0.001-0.2 \mathrm{~mol} / \mathrm{L})$ and $0.45 \mathrm{~g}$ of $\mathrm{Tb}_{2} \mathrm{O}_{3}$ were placed in a $25 \mathrm{~mL}$ Teflon-lined autoclave. The autoclave was sealed, heated in an electric oven to $200^{\circ} \mathrm{C}$ at a heating rate of $5^{\circ} \mathrm{C} / \mathrm{min}$, and maintained at $200^{\circ} \mathrm{C}$ for $6 \mathrm{~h}$ with rotation for agitation. The autoclave was then cooled to room temperature via air quenching. The precipitate was collected using a centrifuge, washed with distilled water, and dried at room temperature. In order to investigate the formation mechanism, the reaction temperature and reaction time were systematically changed. In addition, 
sodium hydroxide and the other type of solutions were used as a solvent instead of acetic acid solution.

\subsection{Characterization}

Powder X-ray diffractions (XRD) were performed using a Rigaku RTP-300RC diffractometer operating at $40 \mathrm{kV}$ and $20 \mathrm{~mA}$ with $\mathrm{CuK} \alpha$ radiation $(\lambda ; 0.15418 \mathrm{~nm})$. The patterns were collected in the range of 5 to $70^{\circ}$ with a $0.02^{\circ}$ step and scanning speed of $4^{\circ} / \mathrm{min}$. The micrographs by field emission scanning electron microscopy (FE-SEM) were obtained using a JEOL JSM-6500F electron microscope operating at $15 \mathrm{kV}$. Fourier transform infrared (FT-IR) spectra were obtained using a Shimadzu FTIR-8200PC spectrophotometer at room temperature.

\section{Result and discussion}

\subsection{Influence of acetic acid concentration}

Figure 1 shows the XRD patterns of the as-prepared samples in $\mathrm{CH}_{3} \mathrm{COOH}$ solutions with different concentrations. It is easy to find that the XRD patterns can be indexed to be a pure hexagonal phase of $\mathrm{Tb}(\mathrm{OH})_{3}$, in agreement with the reported data (JCPDS 83-2038) when the concentration of $\mathrm{CH}_{3} \mathrm{COOH}$ was lower than $0.15 \mathrm{M}$ [Figs. 1(a)-1(e)]. With the increase in concentration of $\mathrm{CH}_{3} \mathrm{COOH}$, the intensity of main diffraction peak (100) was gradually reduced, meanwhile the full width at half maximum (FWHM) was increased. This result indicates that the crystallinity of the products was gradually decreased. It is important to note that the relative intensity ratio of (110) and (101) diffraction was changed with the increase in concentration of $\mathrm{CH}_{3} \mathrm{COOH}$, suggesting that the preferential growth along $c$-axis occurred with the increase in concentration of $\mathrm{CH}_{3} \mathrm{COOH}$. When the concentration was further increased to $0.2 \mathrm{M}$ [Fig. 1(f)], an unknown phase was formed. The peak located at $2 \theta=6.76^{\circ}$ suggests an interlayer d-spacing of $1.306 \mathrm{~nm}$, and the peaks with relatively low intensity at $2 \theta=13.56^{\circ}$ and $20.36^{\circ}$ can be assigned to its secondorder and third-order reflection, respectively. Therefore, the above $\mathrm{d}$ values of the XRD patterns show that a compound with the layered structure was formed in $0.2 \mathrm{M} \mathrm{CH}_{3} \mathrm{COOH}$ solution.

In order to characterize the unknown phase, the infrared spectra were measured. Figure S1 (Supplementary file) shows the FT-IR spectra of the as-prepared samples. The $\mathrm{Tb}(\mathrm{OH})_{3}$ products [Figs. S1(a)-S1(e)] had the same absorption at 3610 and 670

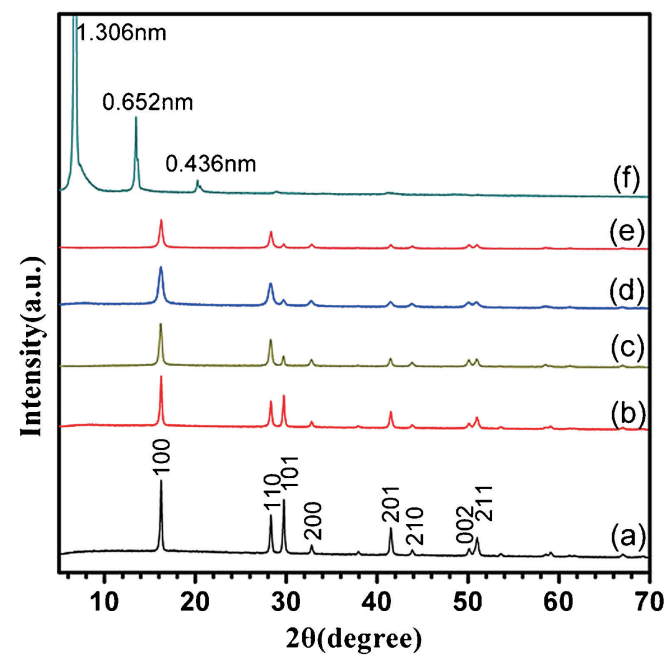

Fig. 1. XRD patterns of the products prepared in $\mathrm{CH}_{3} \mathrm{COOH}$ solutions with different concentrations of (a) $0.001 \mathrm{M}$, (b) $0.01 \mathrm{M}$, (c) $0.03 \mathrm{M}$, (d) $0.067 \mathrm{M}$, (e) $0.15 \mathrm{M}$, and (f) $0.2 \mathrm{M}$. $\mathrm{cm}^{-1}$. In accordance to the literature ${ }^{8)}$ these two bands can be associated with $\mathrm{O}-\mathrm{H}$ stretching vibration of $\mathrm{Tb}(\mathrm{OH})_{3}$ and with $\mathrm{Tb}-\mathrm{O}-\mathrm{H}$ bending vibration. The FT-IR spectra of the unknown phase [Fig. S1(f)] show that the occurrence of a broad 3380 $\mathrm{cm}^{-1}$ band may be attributed to residual absorbed water in the sample, the bands at 2924 and $2853 \mathrm{~cm}^{-1}$ correspond to $-\mathrm{CH}_{3}$ stretching and $-\mathrm{CH}_{3}$ against stretching vibration, respectively. ${ }^{19)}$ The bands located between 1568 and $1443 \mathrm{~cm}^{-1}$ are typical for asymmetric stretching vibrations and symmetric stretching vibrations of carboxylate groups $\mathrm{COO}^{-}$, respectively. On the basis of the IR spectra, the sample (f) might contain acetate hydrate.

The SEM images of the several typical samples with distinct morphologies are presented in Fig. 2. $\mathrm{Tb}(\mathrm{OH})_{3}$ could be obtained at the concentration between 0.001 and $0.15 \mathrm{M}$ [Figs. 2(a)-2(e)]. At low $\mathrm{CH}_{3} \mathrm{COOH}$ concentration of $0.001 \mathrm{M}$ [Fig. 2(a)], the obtained product was composed of granular aggregates and it is difficult to distinguish each particle. By the increase in concentration to $0.01 \mathrm{M}$ [Fig. 2(b)], the morphology was changed to micro-cylinders with diameter of $1.5 \mu \mathrm{m}$ and length up to $5 \mu \mathrm{m}$. It is easy to find that these micro-rods were composed of bundles of nanowires. The diameter of these nanowires ranges from 50 to $100 \mathrm{~nm}$. As $\mathrm{CH}_{3} \mathrm{COOH}$ concentration was further increased to $0.03 \mathrm{M}$ [Fig. 2(c)], the spindle-like structures with diameter less than $2 \mu \mathrm{m}$ and length longer than $10 \mu \mathrm{m}$ were obtained. In $0.067 \mathrm{M} \mathrm{CH}_{3} \mathrm{COOH}$ solution, the diameter of the spindles was decreased but the length was increased [Fig. 4(c)]. When $\mathrm{CH}_{3} \mathrm{COOH}$ concentration was $0.1 \mathrm{M}$ [Fig. 2(d)], $\mathrm{Tb}(\mathrm{OH})_{3}$ crystallized into homogeneous spindles in shape. The diameter of the spindles was $1 \mu \mathrm{m}$ and the length was $13 \mu \mathrm{m}$. When the concentration was increased further, the bundles of nanowires predominantly split into the nanowires with a wide scale of size, ranging in length between 2 and $10 \mu \mathrm{m}$ [Fig. 2(e)]. When the concentration was $0.2 \mathrm{M}$, the morphology of the product

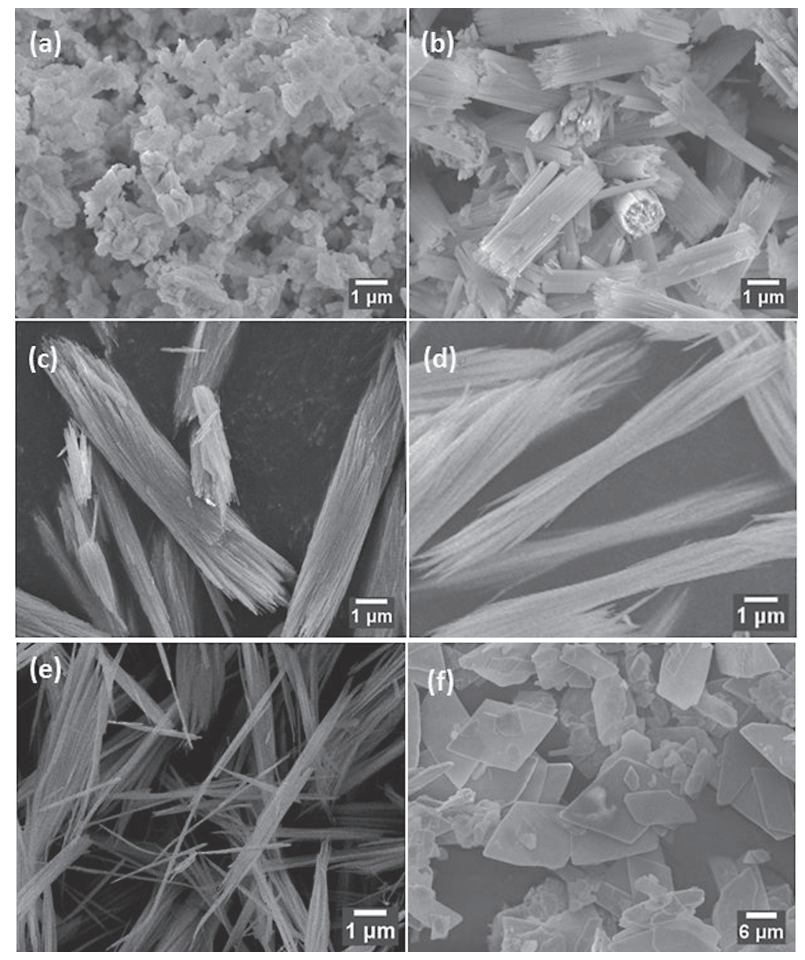

Fig. 2. SEM images of the products prepared in $\mathrm{CH}_{3} \mathrm{COOH}$ solution with different concentration of: (a) $0.001 \mathrm{M}$, (b) $0.01 \mathrm{M}$, (c) $0.03 \mathrm{M}$, (d) $0.1 \mathrm{M}$, (e) $0.15 \mathrm{M}$, (f) $0.2 \mathrm{M}$. 


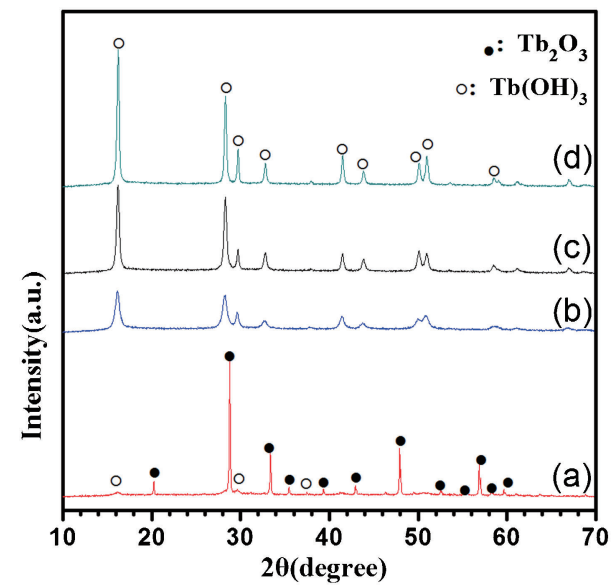

Fig. 3. XRD patterns of the products prepared in $0.067 \mathrm{M} \mathrm{CH}_{3} \mathrm{COOH}$ solution at different temperature of (a) $100^{\circ} \mathrm{C}$, (b) $160^{\circ} \mathrm{C}$, (c) $200^{\circ} \mathrm{C}$, (d) $220^{\circ} \mathrm{C}$ for $6 \mathrm{~h}$.

changed dramatically. The product consisted of plate-like crystals [Fig. 2(f)]. This result is in agreement with the XRD pattern of the product which suggested the product had a layered structure.

\subsection{Effect of reaction temperature}

$\mathrm{Tb}_{2} \mathrm{O}_{3}$ was hydrothermally treated in $0.067 \mathrm{M} \mathrm{CH}_{3} \mathrm{COOH}$ solution at different temperatures from 100 to $220^{\circ} \mathrm{C}$ for $6 \mathrm{~h}$. Figure 3 shows the XRD patterns of the as-prepared samples. A small amount of $\mathrm{Tb}(\mathrm{OH})_{3}$ was formed at $100^{\circ} \mathrm{C}$ and a large amount of the unreacted raw material $\mathrm{Tb}_{2} \mathrm{O}_{3}$ remained [Fig. 3(a)]. With the increase in reaction temperature to $160^{\circ} \mathrm{C}$ [Fig. 3(b)], the diffractions of the raw material $\mathrm{Tb}_{2} \mathrm{O}_{3}$ disappeared and the product was the pure phase of $\mathrm{Tb}(\mathrm{OH})_{3}$. When the temperature was increased further [Figs. 3(c) and 3(d)], the crystallinity of $\mathrm{Tb}(\mathrm{OH})_{3}$ was significantly increased.

Figure 4 shows typical SEM images of the $\mathrm{Tb}(\mathrm{OH})_{3}$ samples as-prepared at different temperatures. The product obtained at $100^{\circ} \mathrm{C}$ consisted of two kinds of particles, spindles and particles with an indefinite form [Fig. 4(a)]. The former must be $\mathrm{Tb}(\mathrm{OH})_{3}$ and the latter could be the unreacted $\mathrm{Tb}_{2} \mathrm{O}_{3}$. When the reaction temperature was $160^{\circ} \mathrm{C}$, bundles composed of $\mathrm{Tb}(\mathrm{OH})_{3}$ nanowires with length of about $13 \mu \mathrm{m}$ were obtained [Fig. 4(b)]. With the increase in reaction temperature to $200^{\circ} \mathrm{C}$, the width of spindle-like bundles was gradually decreased, as shown in Fig. 4(c). The size of the spindles obtained at $220^{\circ} \mathrm{C}$ was decreased to $0.5 \mu \mathrm{m}$ in diameter and $3-5 \mu \mathrm{m}$ in length [Fig. 4(d)]. The spindles were composed of nanowires and the diameter of a nanowire was increased by increasing reaction temperature [the insets of Figs. 4(b) and 4(d)]. In addition, it is clearly found that the growth direction of $\mathrm{Tb}(\mathrm{OH})_{3}$ nanowires prepared at $160^{\circ} \mathrm{C}$ is non-uniform, as observed in the inset of Fig. 4(b). Those nanowires grew along the various directions, gathered at an angle into a bundle. However, the $\mathrm{Tb}(\mathrm{OH})_{3}$ nanowires obtained at $220^{\circ} \mathrm{C}$ grew in the same direction [inset of Fig. 4(d)]. The growth directions of those nanowires are uniformly along the $c$ axis. Combining with the results of $\mathrm{XRD}$, the crystallinity of $\mathrm{Tb}(\mathrm{OH})_{3}$ prepared at $160^{\circ} \mathrm{C}$ is obviously lower than $220^{\circ} \mathrm{C}$. We speculated that the $\mathrm{Tb}(\mathrm{OH})_{3}$ nanowires prepared at $160^{\circ} \mathrm{C}$ might not be the single crystals.

\subsection{Effect of reaction time}

In order to understand the formation mechanism, the reaction time was changed from 0 to $24 \mathrm{~h}$, while the $\mathrm{CH}_{3} \mathrm{COOH}$ concentration and reaction temperature were fixed to $0.067 \mathrm{M}$ and

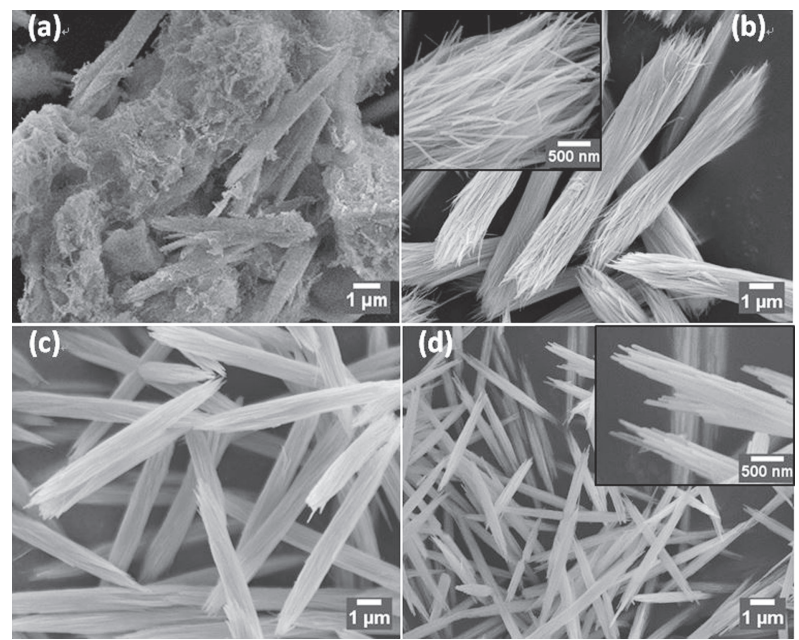

Fig. 4. SEM images of the products prepared in $0.067 \mathrm{M} \mathrm{CH}_{3} \mathrm{COOH}$ solution at different temperature of (a) $100^{\circ} \mathrm{C}$, (b) $160^{\circ} \mathrm{C}$, (c) $200^{\circ} \mathrm{C}$ (d) $220^{\circ} \mathrm{C}$ for $6 \mathrm{~h}$.

$200^{\circ} \mathrm{C}$, respectively. Figure S2 shows the XRD patterns of the samples obtained by the reaction for $0 \mathrm{~h}$ (just when the oven reached $200^{\circ} \mathrm{C}$ at a heating ramp of $\left.5^{\circ} \mathrm{C} / \mathrm{min}\right), 0.5,2,6$ and $24 \mathrm{~h}$. The characteristic peaks of hexagonal $\mathrm{Tb}(\mathrm{OH})_{3}$ began to appear in the XRD patterns of the sample obtained just after the oven reached $200^{\circ} \mathrm{C}$ [Fig. S2(a)]. Most of the diffraction peaks were proved to be the raw material $\mathrm{Tb}_{2} \mathrm{O}_{3}$. The single phase of $\mathrm{Tb}(\mathrm{OH})_{3}$ could be obtained by the hydrothermal reaction for 30 min, and with the increase in reaction time, the intensity of main diffraction peak (100) gradually increase [Figs. S2(b)-S2(d)]. This result suggests that the crystallinity was increased with the increase in reaction time.

Figure 5 shows SEM images of the samples received after the hydrothermal reaction at $200^{\circ} \mathrm{C}$ for different reaction time. When the oven reached $200^{\circ} \mathrm{C}$, the product was composed of small spindles and infinite shaped particles [Fig. 5(a)]. The spindles must be $\mathrm{Tb}(\mathrm{OH})_{3}$ and the other particles must be the unreacted $\mathrm{Tb}_{2} \mathrm{O}_{3}$. With the increase in reaction time to $0.5 \mathrm{~h}$ [Fig. $\left.5(\mathrm{~b})\right]$, the spindles with diameter of $1.5 \mu \mathrm{m}$ and length longer than $5 \mu \mathrm{m}$ were obtained. It is easy to find that these spindles are bundles of nanowires. As the reaction time was further increased to $6 \mathrm{~h}$ [Fig. 4(c)], the diameter of the spindle-like structures was slightly decreased and the length was increased. Finally, by the long reaction time of $24 \mathrm{~h}$, the tips of the spindle-like bundles began to split lightly into nanowires [Fig. 5(c)].

\subsection{Formation mechanism of spindle-like archi- tectures of terbium hydroxide}

The results described above suggest that $\mathrm{CH}_{3} \mathrm{COOH}$ plays a key role in determining the morphology of the spindle-like architectures. The morphology of growing crystals is determined by the relative growth rate of different crystal faces. $\mathrm{Tb}(\mathrm{OH})_{3}$ has the hexagonal structure, so that crystals of $\mathrm{Tb}(\mathrm{OH})_{3}$ are expected to grow in hexagonal prisms with large prismatic planes or hexagonal plates with large basal planes. In $\mathrm{CH}_{3} \mathrm{COOH}$ solutions, $\mathrm{Tb}(\mathrm{OH})_{3}$ crystals grew in the $c$ axis direction to form nanowires. It is considered that $\mathrm{CH}_{3} \mathrm{COO}^{-}$ions adsorb on prismatic planes and inhibit the growth of prismatic planes. As a consequence, $\mathrm{Tb}(\mathrm{OH})_{3}$ crystals grow in the $c$ axis direction.

To get a further understanding of the effect of $\mathrm{CH}_{3} \mathrm{COOH}$, $0.067 \mathrm{M}$ of sodium hydroxide $(\mathrm{NaOH})$, sodium acetate 


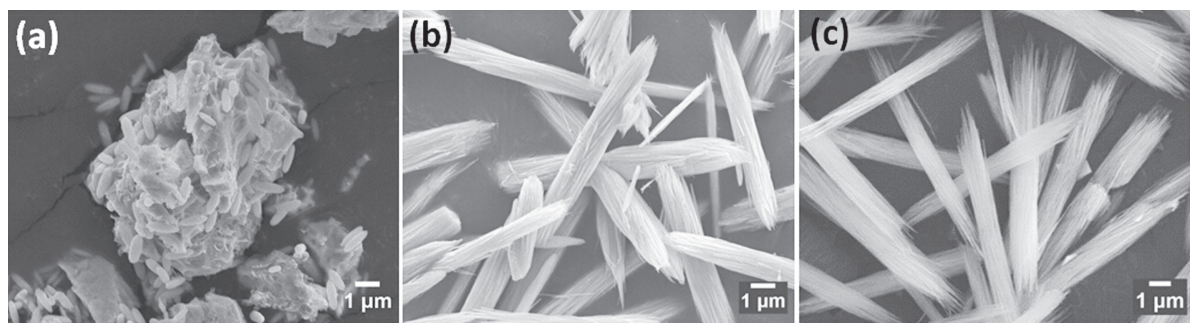

Fig. 5. SEM images of the products prepared in $0.067 \mathrm{M} \mathrm{CH}_{3} \mathrm{COOH}$ at $200^{\circ} \mathrm{C}$ for different time: (a) $0 \mathrm{~h}$, (b) $0.5 \mathrm{~h}$, (c) $24 \mathrm{~h}$.

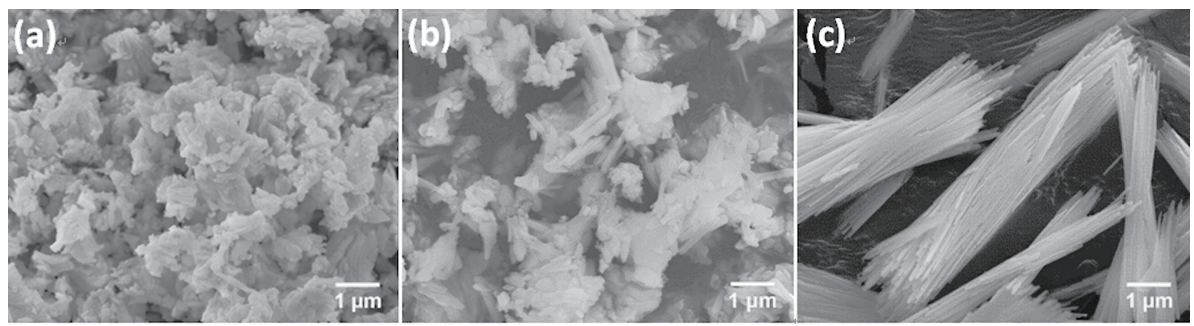

Fig. 6. SEM images of the products synthesized from $0.45 \mathrm{~g}$ of $\mathrm{Tb}_{2} \mathrm{O}_{3}$ in (a) $0.067 \mathrm{M} \mathrm{NaOH}$ solution, (b) $0.067 \mathrm{M}$ $\mathrm{CH}_{3} \mathrm{COONa}$, (c) $0.067 \mathrm{M} \mathrm{CH}_{3} \mathrm{COONH}_{4}$.

$\left(\mathrm{CH}_{3} \mathrm{COONa}\right)$ and ammonium acetate $\left(\mathrm{CH}_{3} \mathrm{COONH}_{4}\right)$ solutions were used as a solvent to compare with $0.067 \mathrm{M} \mathrm{CH}_{3} \mathrm{COOH}$ solution. The $\mathrm{pH}$ values of $0.067 \mathrm{M}$ of $\mathrm{NaOH}, \mathrm{CH}_{3} \mathrm{COONa}$, $\mathrm{CH}_{3} \mathrm{COONH}_{4}$ and $\mathrm{CH}_{3} \mathrm{COOH}$ solutions were $12.8,8.65,7.12$ and 3.28, respectively. The pure phase of $\mathrm{Tb}(\mathrm{OH})_{3}$ was obtained in all kinds of solutions, as shown in Fig. S3. However, the relative intensity ratio of (110) and (101) diffraction were different from each other. This result suggests that the degree of orientation of $\mathrm{Tb}(\mathrm{OH})_{3}$ crystals is different, depending on the solvents. The intensity of (101) peak against that of (110) peak was increased in the following order: $\mathrm{NaOH}, \mathrm{CH}_{3} \mathrm{COONa}$, $\mathrm{CH}_{3} \mathrm{COONH}_{4}$, and $\mathrm{CH}_{3} \mathrm{COOH}$, which is the same order of alkalinity of the solutions.

Figure 6 shows SEM images of the products obtained in different solvents. As shown in Fig. 6(a), the product obtained in $\mathrm{NaOH}$ was composed of nanoparticle aggregates. The products composed of rods and nanoparticles were obtained in $\mathrm{CH}_{3}$ COONa [Fig. 6(b)], while bundles of $\mathrm{Tb}(\mathrm{OH})_{3}$ nanowires were formed in $\mathrm{CH}_{3} \mathrm{COONH}_{4}$ [Fig. 6(c)]. The morphologies of the products obtained in the solutions including the same amount of $\mathrm{CH}_{3} \mathrm{COO}^{-}$ions were different from each other, depending on their $\mathrm{pH}$ value. The length and width of the bundles obtained in $0.067 \mathrm{M} \mathrm{CH}_{3} \mathrm{COONH}_{4}$ were larger and the tips of the bundles lightly split into nanowires, compared with those obtained in $0.067 \mathrm{M} \mathrm{CH}_{3} \mathrm{COOH}$ [Fig. 4(c)]. It is concluded that the adsorption of $\mathrm{CH}_{3} \mathrm{COO}^{-}$ions occurred in neutral and acidic solutions but not in basic solutions.

A proposed formation process seems to be responsible for the observed development of morphologies of $\mathrm{Tb}(\mathrm{OH})_{3}$ synthesized in various solutions. The key elements of this mechanism involve the $\mathrm{pH}$ value and the concentration of acetate ions of the initial solution. In a basic solution of $\mathrm{NaOH}$, nanoparticles are formed because the uniform adsorption of $\mathrm{OH}^{-}$ions on the crystal surfaces may not cause the oriented growth of the hydroxide crystals. In dilute $\mathrm{CH}_{3} \mathrm{COOH}$ solutions, $\mathrm{Tb}(\mathrm{OH})_{3}$ crystals grow promiscuously into nanoparticles without the orientation growth. With the increase in the concentration of $\mathrm{CH}_{3} \mathrm{COOH}, \mathrm{Tb}(\mathrm{OH})_{3}$ crystals grow directionally along the $c$ axis to form nanowires by inhibition of the growth of prismatic planes due to the adsorption of $\mathrm{CH}_{3} \mathrm{COO}^{-}$ions. These nanowires were aggregated together to form bundles of nanowires and spindle-like architectures in order to reduce the surface energy. With the further increase in the concentration of $\mathrm{CH}_{3} \mathrm{COOH}$ solutions, the excess $\mathrm{CH}_{3} \mathrm{COO}^{-}$ ions adsorb on the surface of nanowires, blocking the formation the spindle-like architectures.

As described above, the transformation of $\mathrm{Tb}_{2} \mathrm{O}_{3}$ to $\mathrm{Tb}(\mathrm{OH})_{3}$ in $0.067 \mathrm{M} \mathrm{CH}_{3} \mathrm{COOH}$ solution is very fast. At the initial stage of the reaction, short nanowires of $\mathrm{Tb}(\mathrm{OH})_{3}$ might be formed and these nanowires tend to align side by side and fuse together spontaneously by the oriented attachment to form the small spindle-like particles as observed in Fig. 5(a). These spindles grow larger by the reaction up to $0.5 \mathrm{~h}$ at $200^{\circ} \mathrm{C}$ [Fig. 5(b)]. At this moment, the starting oxide has been completely exhausted. These spindles are composed of the nanowires, but the orientation of nanowires along the $c$ axis is not complete and some defects exist between nanowires. When the reaction time is increased, the width of the spindles is decreased and the tips of the bundles split into nanowires by the dissolution and recrystallization process, which results in increase in the crystallinity (Fig. S2). At high temperature, the transformation of $\mathrm{Tb}_{2} \mathrm{O}_{3}$ to $\mathrm{Tb}(\mathrm{OH})_{3}$ is further accelerated, which results in formation of a large number of small $\mathrm{Tb}(\mathrm{OH})_{3}$ spindles composed of high crystalline nanowires with orientation along the $c$ axis.

Figure 7 shows the XRD patterns of the product obtained by calcination at $800^{\circ} \mathrm{C}$ for $2 \mathrm{~h}$ from $\mathrm{Tb}(\mathrm{OH})_{3}$ prepared in $0.067 \mathrm{M}$ $\mathrm{CH}_{3} \mathrm{COOH}$ at $200^{\circ} \mathrm{C}$ for $6 \mathrm{~h}$. It is shown that the pure phase of $\mathrm{Tb}_{4} \mathrm{O}_{7}$ was obtained after calcination of $\mathrm{Tb}(\mathrm{OH})_{3}$ at $800^{\circ} \mathrm{C}$. As shown in inset of Fig. 7, the $\mathrm{Tb}_{4} \mathrm{O}_{7}$ particles were spindle-like in shape. The morphology of the $\mathrm{Tb}_{4} \mathrm{O}_{7}$ particles retained that of the $\mathrm{Tb}(\mathrm{OH})_{3}$ particles, even after the transformation to the oxide. However, a slight decrease of the particle size was observed due to the higher density of the oxide. Thus, the $\mathrm{Tb}(\mathrm{OH})_{3}$ spindles can be converted into $\mathrm{Tb}_{4} \mathrm{O}_{7}$ without morphological deformation by calcination. This is an important basis for the preparation of rare earth oxides with various morphologies from hydroxides prepared by adjustment of hydrothermal reactions. 


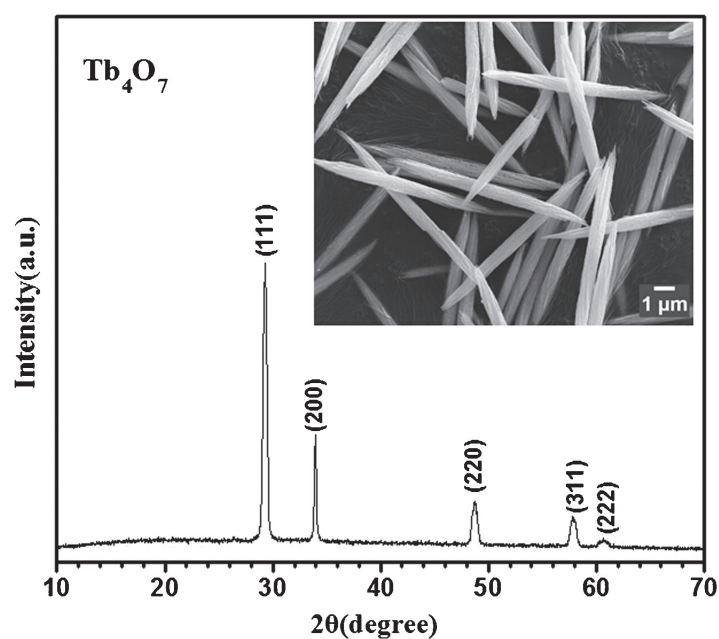

Fig. 7. XRD patterns and SEM image of the product obtained by calcination at $800^{\circ} \mathrm{C}$ for $2 \mathrm{~h}$ from $\mathrm{Tb}(\mathrm{OH})_{3}$ prepared in $0.067 \mathrm{M} \mathrm{CH}_{3} \mathrm{COOH}$ at $200^{\circ} \mathrm{C}$ for $6 \mathrm{~h}$.

\section{Conclusion}

The spindle-like architectures consisting of $\mathrm{Tb}(\mathrm{OH})_{3}$ nanowires were successfully produced from $\mathrm{Tb}_{2} \mathrm{O}_{3}$ by hydrothermal treatments in acetic acid solutions. The concentration of acetic acid, reaction temperature, reaction time and types of solvents strongly affected the morphology and size of the products. The morphology of the $\mathrm{Tb}(\mathrm{OH})_{3}$ products were changed from granular aggregates, micro-cylinders composed of nanowires, spindles composed of nanowires and to separated wires with the increase in concentration of $\mathrm{CH}_{3} \mathrm{COOH}$. The $\mathrm{CH}_{3} \mathrm{COO}^{-}$ions adsorbed on prismatic planes of $\mathrm{Tb}(\mathrm{OH})_{3}$ crystals with the hexagonal crystal structure and inhibited the growth of prismatic planes, which resulted in the oriented growth of $\mathrm{Tb}(\mathrm{OH})_{3}$ in the $c$ axis direction. The crystallinity of the $\mathrm{Tb}(\mathrm{OH})_{3}$ products was increased by enhancing reaction temperature and reaction time. The method utilized in this study to fabricate $\mathrm{Tb}(\mathrm{OH})_{3}$ crystals is a general one-step hydrothermal route and could be extended to synthesize the other rare earth hydroxides with tunable morphologies by simply adjusting the concentration of acetic acid.

\section{References}

1) X. Zhang, P. Hu, Y.-B. Cao and W.-C. Xiang, CrystEngComm, 13, 3057-3063 (2011).

2) Y. Zeng, Z. Li, Y. Liang, X. Gan and M. Zheng, Inorg. Chem., 52, 9590-9596 (2013).

3) S. Liu, Y. Liu, Q. Mu, F. Zhang, H. Li and Y. Wang, Appl. Phys. A, 111, 1229-1240 (2013).

4) X. Wang and Y. Li, Chem. Eur. J., 9, 5627-5635 (2003).

5) W. Bu, L. Zhang, Z. Hua, H. Chen and J. Shi, Cryst. Growth Des., 7, 2305-2309 (2007).

6) Z. Xu, C. Li, P. Yang, C. Zhang, S. Huang and J. Lin, Cryst. Growth Des., 9, 4752-4758 (2009).

7) Q. Tang, J. Shen, W. Zhou, W. Zhang, W. Yu and Y. Qian, J. Mater. Chem., 13, 3103-3106 (2003).

8) Y. Sohn, Ceram. Int., 40, 13803-13811 (2014).

9) M. Yang, H. You, Y. Song, Y. Huang, G. Jia, K. Liu, Y. Zheng, L. Zhang and H. Zhang, J. Phys. Chem. C, 113, 20173-20177 (2009).

10) N. Li and K. Yanagisawa, J. Solid State Chem., 181, 17381743 (2008).

11) H. Zheng, K. Zhu, Q. Wu, J. Liu and J. Qiu, J. Cryst. Growth, 363, 300-307 (2013)

12) K. Zhu, Y. Cao, X. Wang, L. Bai, J. Qiu and H. Ji, CrystEngComm, 14, 411-416 (2012).

13) P. Liu, K. Zhu, Y. Gao, Q. Wu, J. Liu, J. Qiu, Q. Gu and H. Zheng, CrystEngComm, 15, 2753-2760 (2013).

14) M. Watanabe and S. Fujihara, J. Solid State Chem., 210, 130137 (2014)

15) M. Hirano and H. Dozono, J. Solid State Chem., 204, 335-340 (2013).

16) J. Yang, C. Li, Z. Quan, C. Zhang, P. Yang, Y. Li, C. Yu and J. Lin, J. Phys. Chem. C, 112, 12777-12785 (2008).

17) P. Wang, B. Bai, L. Huang, S. Hu, J. Zhuang and X. Wang, Nanoscale, 3, 2529-2535 (2011).

18) F. Tao, Z. Wang, L. Yao, W. Cai and X. Li, Nanotech., 17, 1079-1082 (2006)

19) W. Liu, J. Jiang, D. Du and D. P. Arnold, Aust. J. Chem., 53, 131-135 (2000). 